Research Paper

\title{
Preliminary Observation about Alteration of Proteins and Their Potential Functions in Spinal Cord of SOD1 G93A Transgenic Mice
}

Jie Zhang ${ }^{1^{*}}$, Ping Huang ${ }^{1,2^{*}}$, Chengsi $\mathrm{Wu}^{1^{*}}$, Huiting Liang ${ }^{1}$, Yue $\mathrm{Li}^{3}$, Lei Zhu ${ }^{1}$, Yi Lu${ }^{1}$, Chunyan Tang ${ }^{1}$ and Renshi $\mathrm{Xu}^{1 \bowtie}$

1. Department of Neurology, the First Affiliated Hospital of Nanchang University, Nanchang 330006, Jiangxi, China

2. Department of Nutrition, the First Affiliated Hospital of Nanchang University, Nanchang 330006, Jiangxi, China

3. Department of Health Statistics, Nanchang University, Nanchang 330006, Jiangxi, China

* indicated the equal contributors

$\square$ Corresponding author: Renshi Xu, Department of Neurology, the First Affiliated Hospital of Nanchang University, Nanchang, Jiangxi 330006, China. Email address: xurenshi@ncu.edu.cn or 13767015770@163.com.

(c) Ivyspring International Publisher. This is an open access article distributed under the terms of the Creative Commons Attribution (CC BY-NC) license (https://creativecommons.org/licenses/by-nc/4.0/). See http://ivyspring.com/terms for full terms and conditions.

Received: 2018.04.22; Accepted: 2018.06.22; Published: 2018.07.27

\begin{abstract}
The protein abnormality participates in the development of ALS that meets with the widespread approval from major researchers. However, these currently found abnormal proteins aren't far enough to explain all pathogenesis of ALS. Therefore, the search of novel abnormal proteins participated in the pathogenesis of ALS is very necessary. In this study, we screened, compared and analyzed the differentially expressed proteins in the spinal cord of the SODI G93A transgenic and wild-type (WT) mice applying the isobaric tags for relative and absolute quantitation (iTRAQ) and the bioinformatics methods. The results revealed the details of significantly differentially expressed proteins between the SODI G93A transgenic and WT mice, and the damaged and/or regulated cellular components, molecular functions and biological processes and the significant enrichment pathways of these proteins. Our study comprehensively described the details of the possible abnormal proteins participated in the pathogenesis of SODI G93A transgenic mice, extensively explored their possible molecular mechanisms how to play the role in the development in this animal model, and provided some evidences and clues for further and deeply studying the relationship between the abnormal proteins and the pathogenesis of ALS in the other animal models and ALS patients.
\end{abstract}

Key words: Amyotrophic lateral sclerosis, Proteomics, iTRAQ, Gene ontology, Cluster of orthologous groups

\section{Introduction}

Amyotrophic lateral sclerosis (ALS) is a progressive disastrous neurological disease, which selectively causes the dysfunction of motor neurons that control muscle voluntary movement. Over time, this disease leads to the muscle weakness and atrophy, gradually spreads to the whole body, especially in the muscles of limbs, pharynx and larynx. In the late stage of ALS, it affects the muscles that control breathing and other vital bodily functions, which results in death [1-3]. ALS is the most common type of motor neuron diseases (MND). In
America, most doctors use the term of ALS to mean MND. ALS is sometimes also referred to as Lou Gehrig's disease because the famous baseball player Lou Gehrig died from this disease in America [3, 4]. The disease was firstly discovered in 1869 by the French neurologist Jean-Martin Charcot, and firstly described in 1874 [5]. ALS is a rare disease, but the patients of rare disease are numerous. In much of the world, the rates of ALS are unknown [6]. According to the epidemiological investigation of the ALS Association, about 6,400 peoples are diagnosed ALS 
every year in America, an estimated 200,000 peoples with ALS live in the world [7-10]. ALS greatly reduces an individual's life expectancy, the average life expectancy of ALS patients after diagnosis is between 3 and 5 years [11]. However, there are many examples of peoples living for much longer, around $20 \%$ of peoples will live five years or more, about $10 \%$ will live for 10 years or more and approximate $5 \%$ will live for a further 20 years after ALS diagnosis [4]. ALS majorly consists of two types: sporadic ALS (Randomly occur) (sALS) and familial ALS (Inherit) (fALS). fALS accounts for around $10 \%$ of cases, the familial members of fALS have about $50 \%$ possibility developing ALS in their next generations [6].

No one knows that what pathogeny causes ALS [4], but two major disease-relevant factors including environments and the genetics are thought to be closely associated with this disease [12-18]. In the aspect of genetic factors, researchers have reported several possible genes and/or loci potentially associated with ALS. In additional, some possible relevant environmental factors also have been found to be related to the development of ALS, such as the chemical pollutants including high levels of agricultural chemicals (Pesticide, chemical fertilizer, herbicide) and factory hazardous air and so on [13, 19-26], the electrical trauma [27], the military service [28], the high levels of exercise [29], the continuous high levels exposure of some heavy metals [30,31] and the chronic virus and bacterial infection [32-36]. Two above described major etiologies of ALS might involve in the following molecular processes: the disorganized immune responses generating the pathologic immune factors may attack some neural cells, subsequently killing nerve cells [37-39]. The chemical imbalance in the endogenous environment like the disorder of neurotransmitter including glutamate in the synaptic gap of the motor neurons produces the toxic to nerve cells [40]. The mishandling of the molecular structure, function and metabolism of proteins, contributing to not processed correctly abnormal proteins produced by nerve cells, which could result in abnormal proteins accumulating in or surrounding neural cells and cause the death of nerve cells [41, 42]. These pathological processes might initiate the deficiencies in mitochondria functions [43-45], the disorder of oxidative regulation [46], the imbalance of calcium homeostasis [47-49], the generation of excitotoxicity [50-52], the abnormal inflammatory responsible $[39,53]$, the production of reactive oxygen species (ROS) [54,55], the excess of autophagy and/or apoptosis of neural cells [56-59], which take part in the pathogenesis of ALS.

The roles of proteins abnormality in the pathogenesis of ALS has recently more and more attracted the researchers' attention and become widely acceptable because the mutation of SOD1 [60], TAR DNA-binding protein 43 (TDP-43) [61, 62], Fused in sarcoma/translocated in liposarcoma (FUS/TLS) [61] and Chromosome 9 open reading frame 72 (C9ORF72) $[63,64]$ proteins were found to participate in the pathogenesis of ALS. However, several proteins found at present can't completely explain the pathogenesis of ALS, might have multiple complex proteins to involve in the pathogenesis of ALS, which need further and deeply be studied. Therefore, in this study, we screened the possible proteins participated in the pathogenesis of ALS using the SOD1 G93A transgenic mice of the currently commonest used animal model in the study of the pathogenesis of ALS applying the isobaric tags for relative and absolute quantitation (iTRAQ) and the bioinformatics methods. The results preliminarily clarified the significantly differently expressed proteins in the spinal cord of SOD1 G93A transgenic mice, analyzed their possible cellular components, molecular functions and biological processes of these significantly differently expressed proteins in the pathogenesis of ALS, indentified several associated pathways that possibly participate in the pathogenesis of ALS, and describing the details of top pathways and their related molecular mechanisms. Our data provided some novel evidences for further and deeply the roles of protein abnormality in the pathogenesis of ALS, and some studied clues for studying the pathogenesis of ALS in the other animal models and ALS patients.

\section{Animals and methods}

\section{Study approval}

All animal studies were conducted in accordance with the guide for the care and use of laboratory animals of China. All experiments involving animal were reviewed and approved by the ethics committee for animal care and use of the First Affiliated Hospital of Nanchang University, China.

\section{Animals}

The line of SOD1 G93A mice (Jackson laboratory, Bar Harbour, Maine) were maintained by mating SOD1 G93A transgenic males with C57BL/6 wild-type (WT) females in the neurological lab of the First Affiliated Hospital of Nanchang University. SOD1 transgenic mice were detected whether or not were positive SOD1 G93A transgenic mice by the PCR of genomic DNA derived from the mice tails. The following primers were used: The forward primer of hmSOD1 G93A was 5'-CAT CAG CCC TAA TCC ATC TGA-3', the reverse primer of hmSOD1 G93A was 5'-CGC GAC TAA CAA TCA AAG TGA-3', the 
forward primer of IL-2 was 5'-CTA GGC CAC AGA ATT GAA AGA TCT-3', the reverse primer of IL-2 was 5'-GTA GGT GGA AAT TCT AGC ATC ATC C-3'. The amplified conditions of PCR were: $94{ }^{\circ} \mathrm{C}$ degeneration for 3 seconds, $60{ }^{\circ} \mathrm{C}$ annealing for 1 minute and $72{ }^{\circ} \mathrm{C}$ extension for 1 minute, total cycles for 35 times. All experimental animals were sacrificed at 68 days (pre-onset stage), 100 days (onset stage) and 130 days (progressive stage) of SOD1 G93A transgenic mice and 124 days of SOD1 WT mouse. At the stage of different disease, the gastrocnemius muscles of abnormal limbs were performed the muscle biopsy and stained by $\mathrm{HE}$, observed the change of muscle structure in light microscope, identified the paralytic serious scale of limb muscles and further decided the pre-onset, onset and progressive stages [65-68]. These protocols were same with our previously used [68, 69].

\section{Protein preparation}

These spinal cord samples token from SOD1 WT and G93A transgenic mice were ground into powders in liquid nitrogen, extracted proteins with lysis buffer (7 M Urea, $2 \mathrm{M}$ Thiourea, 4\% CHAPS, $40 \mathrm{mM}$ Tris- $\mathrm{HCl}, \mathrm{pH}$ 8.5) containing $1 \mathrm{mM}$ PMSF and $2 \mathrm{mM}$ EDTA (Final concentration). After 5 minutes of extraction, $10 \mathrm{mM}$ DTT (Final concentration) was added to these samples. These suspensions were sonicated at $200 \mathrm{~W}$ for 15 minutes and then centrifuged at $4{ }^{\circ} \mathrm{C}, 30,000 \mathrm{~g}$ for 15 minutes. These supernatants were mixed well with $5 \times$ volume of chilled acetone containing $10 \%(\mathrm{v} / \mathrm{v})$ TCA and incubated at $-20{ }^{\circ} \mathrm{C}$ overnight. After centrifugation at $4{ }^{\circ} \mathrm{C}, 30,000 \mathrm{~g}$, these supernatants were discarded. These precipitates were washed with chilled acetone three times. These pellets were air-dried and dissolved in Lysis buffer (7 M urea, $2 \mathrm{M}$ thiourea, $4 \%$ NP40, $20 \mathrm{mM}$ Tris-HCl, $\mathrm{pH}$ 8.0-8.5). These suspensions were sonicated at $200 \mathrm{~W}$ for 15 minutes and centrifuged at $4{ }^{\circ} \mathrm{C}, 30,000 \mathrm{~g}$ for 15 minutes. These supernatants were transferred to another tube. In order to reducing disulfide bonds in the proteins of these supernatants, $10 \mathrm{mM}$ DTT (Final concentration) was added and incubated at $56^{\circ} \mathrm{C}$ for 1 hour, and subsequently, $55 \mathrm{mM}$ IAM (Final concentration) was added to block cysteines, then incubated for 1 hour in darkroom. These supernatants were mixed well with $5 \times$ volume of chilled acetone for 2 hours at $-20^{\circ} \mathrm{C}$ to precipitate proteins. After centrifugation at $4{ }^{\circ} \mathrm{C}$, $30,000 \mathrm{~g}$, these supernatants were discarded, and these pellets were air-dried for 5 minutes, then were dissolved in $500 \mu \mathrm{L} 0.5 \mathrm{M}$ TEAB (Applied Biosystems, Milan, Italy), and were sonicated at $200 \mathrm{~W}$ for 15 minutes. Finally, these samples were centrifuged at 4 ${ }^{\circ} \mathrm{C}, 30,000 \mathrm{~g}$ for 15 minutes. These supernatants were transferred to a new tube and quantified. These proteins in supernatants were kept at $-80{ }^{\circ} \mathrm{C}$ for further analysis [70].

\section{iTRAQ labeling and SCX fractionation}

$100 \mu \mathrm{g}$ proteins took out from each sample and then these proteins were digested using trypsin gold (Promega, Madison, WI, USA) with the 30:1 ratio of protein and trypsin at $37{ }^{\circ} \mathrm{C}$ for 16 hours. After digested by trypsin, these peptides were dried by vacuum centrifugation. These peptides were reconstituted in $0.5 \mathrm{M} \mathrm{TEAB}$ and processed a series of experimental performs according to the manufacture's protocol for 8-plex iTRAQ reagent (Applied Biosystems). Briefly, one unit of iTRAQ reagent was thawed and reconstituted in $24 \mu \mathrm{L}$ isopropanol. Four Samples were labeled with iTRAQ tags as follow procedures: four spinal samples including 1 SOD1 WT mouse (124 days) and 3 G93A SOD1 transgenic mice (Pre-onset, onset and progression stages). These peptides were labeled using the isobaric tags, incubated at room temperature for 2 hours. These labeled peptide mixtures were then pooled and dried by vacuum centrifugation. SCX chromatography was performed by a LC-20AB HPLC Pump system (Shimadzu, Kyoto, Japan). These iTRAQ labeled peptide mixtures were reconstituted with $4 \mathrm{ml}$ buffer $\mathrm{A}(25 \mathrm{mM} \mathrm{NaH} 2 \mathrm{PO} 4$ in $25 \% \mathrm{ACN}, \mathrm{pH} 2.7$ ) and loaded onto a $4.6 \times 250 \mathrm{~mm}$ Ultremex SCX column containing $5 \mu \mathrm{M}$ particles (Phenomenex). These peptides were eluted at a flow rate of $1 \mathrm{ml} / \mathrm{min}$ with a gradient of buffer $\mathrm{A}$ for 10 minutes, 5-60\% buffer B (25 mM NaH2PO4, $1 \mathrm{M} \mathrm{KCl}$ in $25 \% \mathrm{ACN}, \mathrm{pH} 2.7$ ) for 27 minutes, $60-100 \%$ buffer B for 1 minute. The system was then maintained at $100 \%$ buffer B for 1 minute before equilibrating with buffer A for 10 minutes prior to the next injection. Elution was monitored by measuring the absorbance at $214 \mathrm{~nm}$, and fractions were collected every 1 minute. These eluted peptides were pooled into 20 fractions, desalted with a Strata X C18 column (Phenomenex) and vacuum-dried [70].

\section{LC-ESI-MS/MS analysis based on TripleTOF 5600}

Each fraction was resuspended in buffer A (5\% $\mathrm{ACN}, 0.1 \% \mathrm{FA}$ ) and centrifuged at 20,000 $\mathrm{g}$ for 10 minutes, the final concentration of peptide was about $0.5 \mu \mathrm{g} / \mu \mathrm{l}$ on average. $10 \mu \mathrm{l}$ supernatants were loaded on a LC-20AD nanoHPLC (Shimadzu, Kyoto, Japan) by autosampler onto a $2 \mathrm{~cm} \mathrm{C18} \mathrm{trap} \mathrm{column.} \mathrm{Then,}$ these peptides were eluted onto a $10 \mathrm{~cm}$ analytical C18 column (Inner diameter $75 \mu \mathrm{m}$ ) packed in house. These samples were loaded at $8 \mu \mathrm{l} / \mathrm{min}$ for 4 minutes, then the gradient of 35 minutes was run at $300 \mathrm{nl} / \mathrm{min}$ 
starting from 2 to $35 \% \mathrm{~B}$ (95\% ACN, 0.1\% FA), followed by 5 minutes linear gradient to $60 \%$, then followed by 2 minutes linear gradient to $80 \%$, and maintained at $80 \%$ B for 4 minutes, and finally returned to $5 \%$ in 1 minute. Data acquisition was performed with a TripleTOF 5600 System (AB SCIEX, Concord, $\mathrm{ON}$ ) fitted with a Nanospray III source (AB SCIEX, Concord, ON) and a pulled quartz tip as the emitter (New Objectives, Woburn, MA). Data was acquired using an ion spray voltage of $2.5 \mathrm{kV}$, curtain gas of 30 psi, nebulizer gas of 15 psi, and an interface heater temperature of 150 . MS was operated using a $\mathrm{RP}$ of greater than or equal to $30,000 \mathrm{FWHM}$ for TOF MS scans. For IDA, survey scans were acquired in 250 $\mathrm{ms}$ and as many as 30 product ion scans were collected if exceeding a threshold of 120 counts per second (Counts/s) and with a $2+$ to $5+$ charge-state. Total cycle times were fixed to 3.3 seconds. Q2 transmission window was $100 \mathrm{Da}$ for $100 \%$. Four time bins were summed for each scan at a pulser frequency value of $11 \mathrm{kHz}$ through monitoring of the $40 \mathrm{GHz}$ multichannel TDC detector with four-anode channel detect ion. A sweeping collision energy setting of $35 \pm$ $5 \mathrm{eV}$ coupled with iTRAQ adjust rolling collision energy was applied to all precursor ions for collision-induced dissociation. Dynamic exclusion was set for $1 / 2$ of peak width (15 seconds), and then the precursor was refreshed off the exclusion list [70].

\section{Data analysis}

Raw data files acquired from the TripleTOF 5600 were converted into Mascot generic format (MGF) files using Proteome Discoverer software revision 1.2 (PD 1.2, Thermo), [5600 msconverter] and MGF file searched. The identification of proteins was performed using Mascot search engine (Matrix Science, London, UK; version 2.3.02) against human database containing 72,645 sequences. For protein identification, a mass tolerance of $0.05 \mathrm{Da}$ (ppm) was permitted for intact peptide masses and 0.1 Da for fragmented ions with allowance for one missed cleavages in the trypsin digests. Gln- > pyro-Glu (N-term Q), oxidation (M) and deamidated (NQ) were used as the potential variable modifications, and carbamidomethyl (C), iTRAQ8plex (N-term) and iTRAQ8plex $(\mathrm{K})$ were used as fixed modifications. The charge states of peptides were set to +2 and +3 . Specifically, an automatic decoy database search was performed in Mascot by choosing the decoy checkbox, a random sequence of database is generated, which tested for raw spectra as well as the real database. In order to reducing the probability of false peptide identification, only peptides at the $95 \%$ confidence interval by a Mascot probability analysis greater than "identity" were counted as identified, and each confident protein identification involves at least one unique peptide. For protein quantification, it was required that a protein contains at least two unique spectra. The quantitative protein ratios were weighted and normalized by the median ratio in Mascot. We only used the fold changes of $>1.2$ and $<0.833$ with $p$ values $<0.05$ were considered as significant [70].

\section{Function method description}

Functional annotations of the up and down regulated proteins were conducted using the database of Clusters of Orthologous Groups of proteins (COG) (http://www. ncbi.nlm.nih.gov/COG/), the Blast2GO program against the non-redundant protein database (NCBI nr), and the KEGG database (http://www.genome.jp/kegg/pathway. html) were used to classify and group these identified proteins. The COG is the database for protein orthologous classification. Every protein in COG is supposed to derive from a same protein ancestor. Gene Ontology $(\mathrm{GO})$ is an international standardization of gene function classification system, it provides a set of dynamic updating controlled vocabulary to describe genes and gene products attributes in the organism. GO has 3 ontologies which can describe the molecular function, the cellular component and the biological process respectively. The cluster of orthologous KEGG pathway is a collection of manually drawn pathway maps representing our knowledge on the molecular interaction and reaction networks, among them, molecules are represented as nodes, and the biological relationship between two nodes is indicated by a line [70].

\section{Data analysis}

The statistical analysis was performed using the SPSS version 17.0 statistical software (SPSS, Chicago, IL, USA). According to the fold level of proteins, the proteins that the fold ratio compared between two groups was $>1.2$ or $<0.833(1 / 1.2)$ and the $P$ value from the $t$ test of the independent sample was $<0.05$ were regarded as the significantly differentially expressed proteins. The hypergeometric test was used to conduct the GO and pathway enrichment analysis of the differentially expressed proteins. $\mathrm{P}<0.05$ was set as the statistically significant.

\section{Results}

\section{The significantly differentially expressed proteins in the spinal cord between the SOD 1 WT and G93A transgenic mice}

The proteins of significant up-regulation in the spinal cord were 464 in the SOD1 WT mouse vs the pre-onset G93A transgenic mouse, 458 in the SOD1 WT vs the onset, 676 in the SOD1 WT vs the 
progression. The proteins of significant down-regulation were 421, 381 and 480 respectively. The proteins of significant up-regulation were 528 in the pre-onset vs the onset, 521 in the pre-onset vs the progression, 570 in the onset vs the progression. The proteins of significant down-regulation were 479, 299 and 236 respectively (Table 1, Figure 1). The proteins of significant up- and down-regulation were described in the supplementary table 1-12. The details of fold distribution of significantly differentially expressed proteins in the spinal cord of the SOD1 WT mouse vs the progression mouse were presented in the Figure 2.

Table 1. The number of differentially expressed proteins in proteomic identification between the two groups

\begin{tabular}{llll}
\hline Group name & Up regulated protein & Down regulated protein & Total differentially expressed proteins \\
\hline Pre-onset spinal cord VS WT spinal cord & 464 & 421 & 885 \\
Onset spinal cord VS WT spinal cord & 458 & 381 & 839 \\
Progression spinal cord VS WT spinal cord & 676 & 480 & 1,156 \\
Onset spinal cord VS Pre-onset spinal cord & 528 & 479 & 1,007 \\
Progression spinal cord VS Pre-onset spinal cord & 521 & 299 & 820 \\
Progression spinal cord VS Onset spinal cord & 570 & 236 & 806 \\
\hline
\end{tabular}

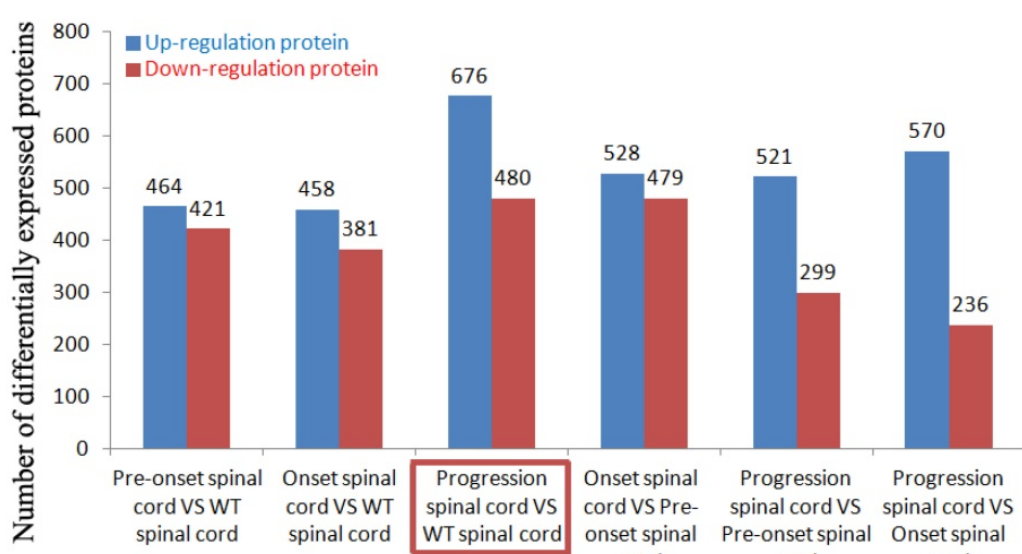

Comparisons between the SOD1 wild and the different stages of G93A transgenic mice, and between the different stages of SOD1 G93A transgenic mice

Figure 1. The number of up and down regulated proteins in the spinal cord of SOD1 G93A transgenic mice compared the SOD 1 G93A mice with the WT mice. The number of up and down regulated proteins in the spinal cord of SOD1 G93A transgenic mice compared between the WT mice and the SODI G93A transgenic mice of the pre-onset, onset and progression stages, and between the pre-onset, onset and progression stages of SODI G93A transgenic mice was shown in Figure. Among them, the most number in the comparison of the WT mice and the SODI G93A transgenic mice of progression stage was marked using the red frame.

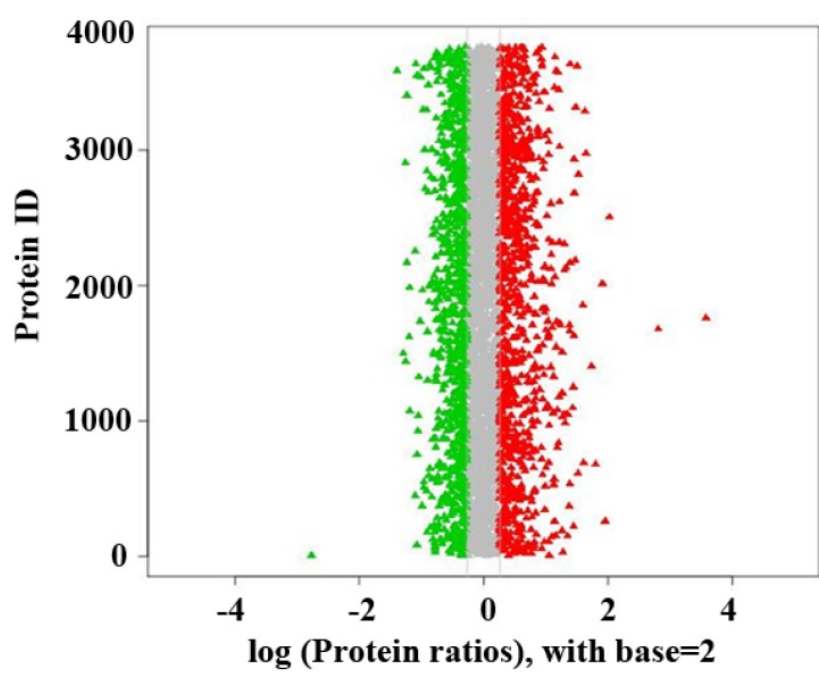

Fold distribution of differentially expressed proteins in spinal cord of SOD1 G93A transgenic mice

Figure 2. The distribution of fold ratio of significantly differentially expressed proteins in the spinal cord of SODI G93A transgenic mice compared between the SOD1 G93A mice and the WT mice. The proteins that Log (Protein ratios) with base $=2$ were larger than 0 were considered as the up regulated proteins. The proteins that Log (Protein ratios) with base $=2$ was smaller than 0 were considered as the down regulated proteins. Among them, the proteins that the fold was larger than 1.2 or less than 0.833 with $p$ values $<0.05$ were considered as the significantly up or down regulated proteins, the red mark was the significantly up regulated proteins, the green mark was the significantly down regulated proteins. 
A

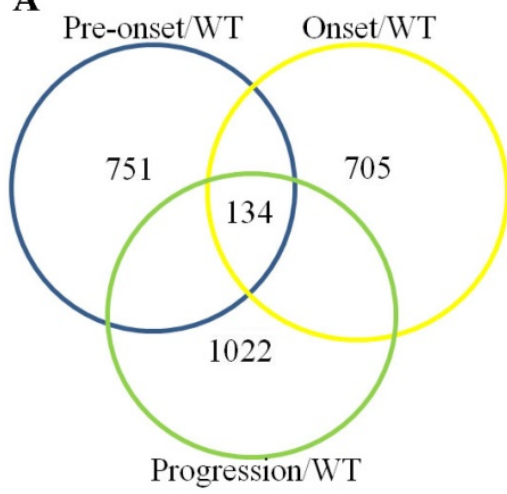

B

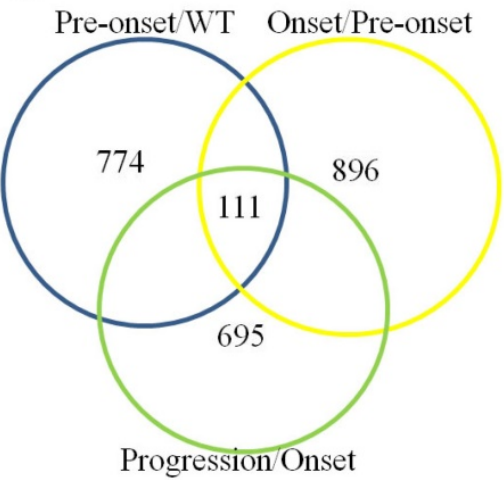

Figure 3. Venn diagram depicting the overlap of significantly differentially expressed proteins identified compared with the SODI G93A transgenic mice of pre-onset, onset and progression stages with the WT mice and compared between the pre-onset, onset and progression stages of SODI G93A transgenic mice. Numbers in parentheses indicate the number of identified significantly differential proteins for the comparison of two groups. (A) The overlapped proteins in the SOD1 G93A mice among the comparison between the pre-onset, onset and progression and the WT mice, the overlapped proteins consisted of 134 proteins in the comparison of three groups (Pre-onset/WT, Onset/WT and Progression/WT). (B) The overlapped proteins in the SODI G93A mice among the comparison between the pre-onset, onset and progression and the WT mice, the overlapped proteins consisted of 111 proteins $\mathrm{n}$ the comparison of three groups.

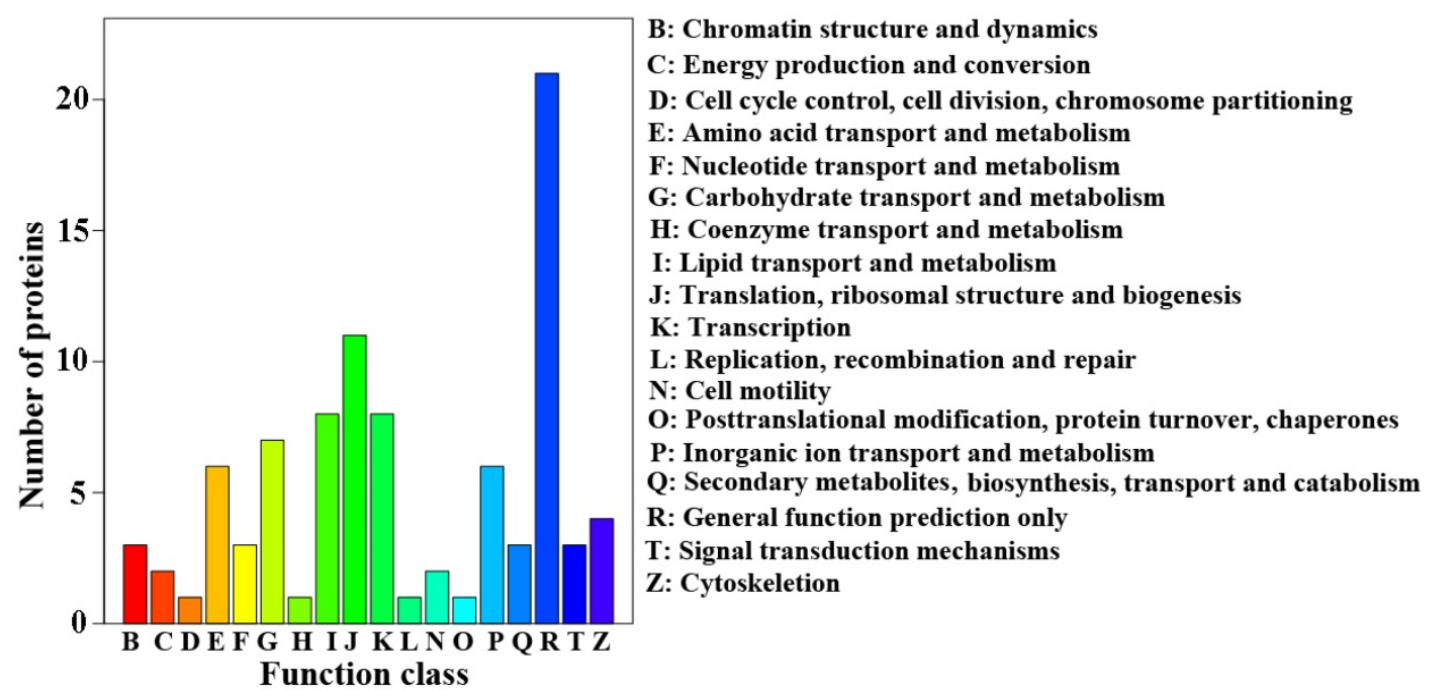

COG function classification of intersection-detail sequence

Figure 4. Map of cluster of orthologous groups (COG) classification of protein. Map of COG classification of significantly differential proteins in the spinal cord of the SODI G93A transgenic mice. The horizontal coordinates in the COG classification map was the entries of the COG classification, the longitudinal coordinates was the corresponding protein number of the functional classification. The figure represented the statistical number of the different functional proteins in the proteins.

\section{The identification of overlapped proteins in three independent comparisons between the SOD1 G93A transgenic mice and the SOD1 WT mouse}

The overlapped proteins in three independent comparisons between the pre-onset, onset and progression SOD1 G93A transgenic mice vs the SOD1 WT mouse consisted of 134 proteins (Figure 3A). The overlapped proteins in three independent comparisons between the pre-onset mouse vs the SOD1 WT mouse, the onset vs the pre-onset and the progression vs the onset consisted of 111 proteins (Figure 3B). The details of the overlapped proteins were shown in the supplementary table 13 and 14 .

\section{The proteins analysis of cluster of orthologous groups (COG) of the significantly differentially expressed proteins in the spinal cord of the SOD1 G93A transgenic mice}

In the function classification of COG, the top of functions were the translation, ribosomal structure and biogenesis, the lipid transport and metabolism, the transcription, the carbohydrate transport and metabolism, the amino acid transport and metabolism, the inorganic ion transport and metabolism, the cytoskeletion, the chromatin structure and dynamics, the secondary metabolites, biosynthesis, transport and catabolism, the signal transduction mechanisms, the energy production and conversion, the cell motility and so on excepted the general functions (Figure 4). 
The gene ontology (GO) enrichment analysis of the significantly differentially expressed proteins in the spinal cord compared the SOD1G93A transgenic mice of the progression stage with the age-matched SOD 1 WT mice

The GO classification showed that the significantly differentially expressed proteins mainly existed in cell $(16.67 \%)$, cell part $(16.67 \%)$, organelle $(15.77 \%)$, organelle part $(13.8 \%)$, macromolecular complex $(9.5 \%)$, membrane $(9.5 \%)$, membrane part $(4.66 \%)$ and membrane-enclosed lumen $(3.23 \%)$ in the cellular components (Figure 5A); in binding (52.76\%), catalytic activity $(20.86 \%)$, structural molecular activity (9.82\%), transport activity $(3.07 \%)$ and molecular transducer activity $(2.45 \%)$ in the molecular functions (Figure 5B); in cellular process (12.62\%), single-organism process $(11.8 \%)$, metabolic process $(11.13 \%)$, cellular component organization or biogenesis $(7.6 \%)$, biological regulation $(6.65 \%)$, regulation of biological process $(5.97 \%)$, localization (5.29\%), response to stimulus (5.29\%), multicellular organismal process $(5.02 \%)$, establishment of localization $(4.88 \%)$, developmental process $(4.34 \%)$, signaling $(3.53 \%)$, positive regulation of biological process $(3.26 \%)$, negative regulation of biological process $(2.99 \%)$, reproduction $(2.17 \%)$ and reproduction process $(2.04 \%)$ in the biological process (Figure 5C). The details of GO in the cellular components, the molecular functions and the biological processes were shown in the supplementary table $15-17$ and the supplementary figure 1-3.
A

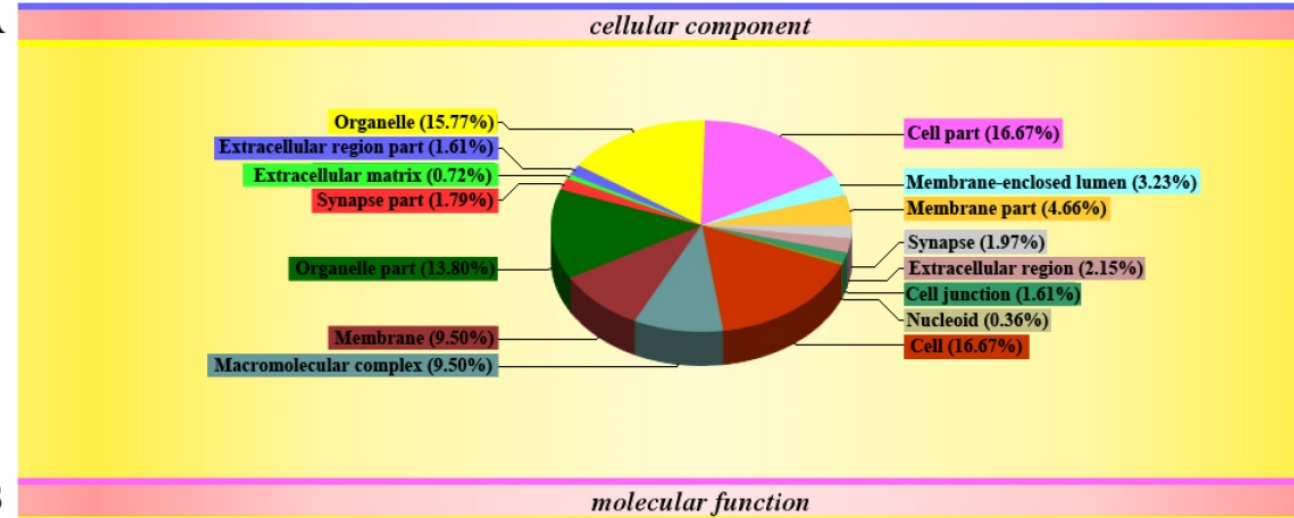

B

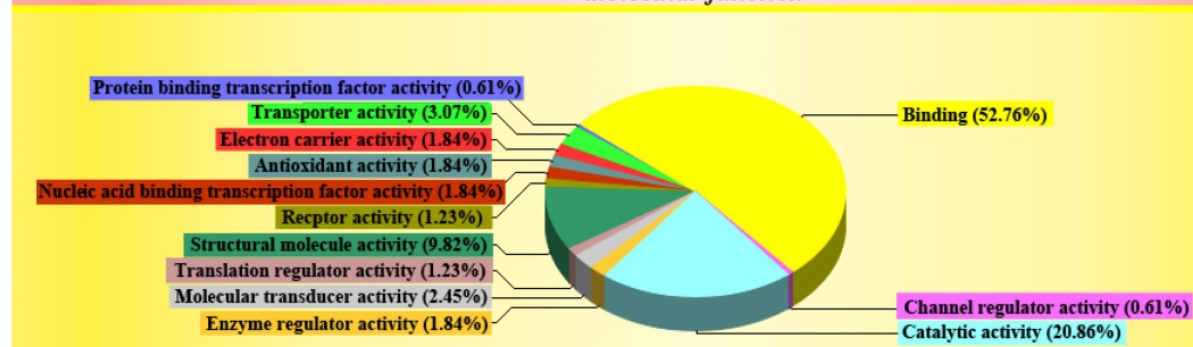

C

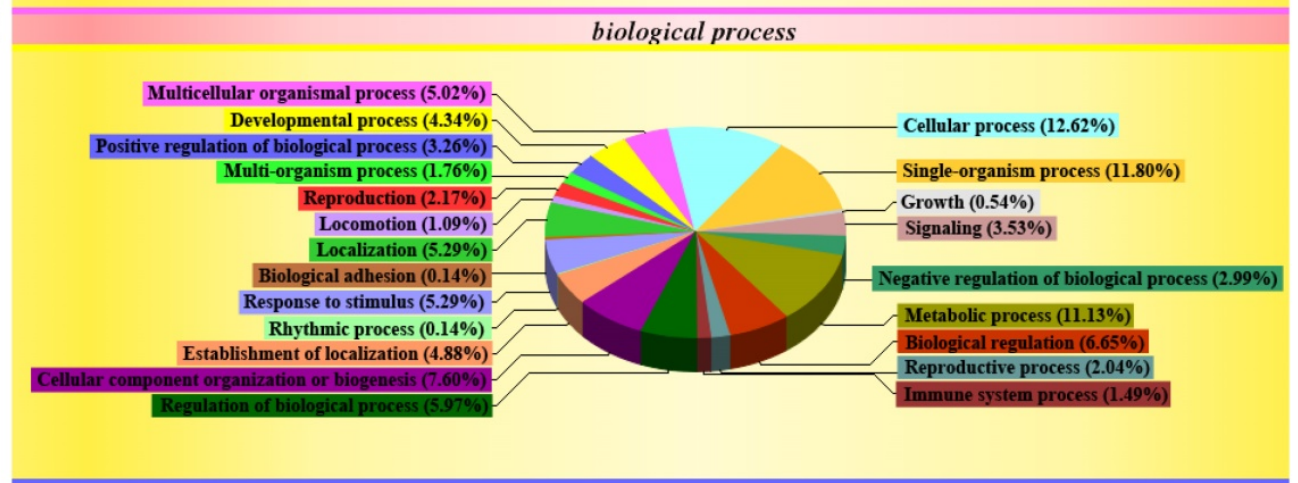

Figure 5. Map of gene ontology (GO) classification of significantly differential proteins in the spinal cord of the SOD1 G93A transgenic mice. The map of GO classification showed the information of three gene ontologies, the cellular component, the cellular function and the biological process. (A) Showed the entries and their percentage in the cellular component. (B) Showed the entries and their percentage in the molecular function. (C) Showed the entries and their percentage in the biological process. The different color marked the individual entries involved in three GO. The pie graphs showed the percentage of the number of individual entries in the number of total proteins. 
Table 2. Significantly orthologous enriched pathways of WT spinal cord vs progression spinal cord

\begin{tabular}{|c|c|c|c|c|}
\hline Significantly orthologous enriched pathway & $\begin{array}{l}\text { Differential proteins with pathway annotation } \\
(519)\end{array}$ & $\begin{array}{l}\text { All proteins with pathway annotation } \\
(4384)\end{array}$ & $P$ value & Pathway ID \\
\hline Ribosome & $25(4.82 \%)$ & $81(1.85 \%)$ & 3.32327E-06 & ko03010 \\
\hline Systemic lupus erythematosus & $15(2.89 \%)$ & $36(0.82 \%)$ & 5.32591E-06 & ko05322 \\
\hline Adherens junction & $18(3.47 \%)$ & $78(1.78 \%)$ & 0.003584906 & ko04520 \\
\hline Phagosome & $18(3.47 \%)$ & $86(1.96 \%)$ & 0.01044217 & ko04145 \\
\hline Pathogenic Escherichia coli infection & $15(2.89 \%)$ & $69(1.57 \%)$ & 0.01320799 & ko05130 \\
\hline Leukocyte transendothelial migration & $19(3.66 \%)$ & $98(2.24 \%)$ & 0.01925641 & ko04670 \\
\hline Wnt signaling pathway & $15(2.89 \%)$ & $72(1.64 \%)$ & 0.01929083 & ko04310 \\
\hline Rheumatoid arthritis & $6(1.16 \%)$ & $20(0.46 \%)$ & 0.02419915 & ko05323 \\
\hline Huntington's disease & $23(4.43 \%)$ & $128(2.92 \%)$ & 0.02526863 & ko05016 \\
\hline Lysosome & $15(2.89 \%)$ & $77(1.76 \%)$ & 0.03386784 & ko04142 \\
\hline Amino sugar and nucleotide sugar metabolism & $9(1.73 \%)$ & $39(0.89 \%)$ & 0.03481863 & ko00520 \\
\hline Amoebiasis & $14(2.7 \%)$ & $71(1.62 \%)$ & 0.03607711 & ko05146 \\
\hline Synaptic vesicle cycle & $13(2.5 \%)$ & $65(1.48 \%)$ & 0.03833252 & ko04721 \\
\hline Staphylococcus aureus infection & $4(0.77 \%)$ & $12(0.27 \%)$ & 0.0442186 & ko05150 \\
\hline
\end{tabular}

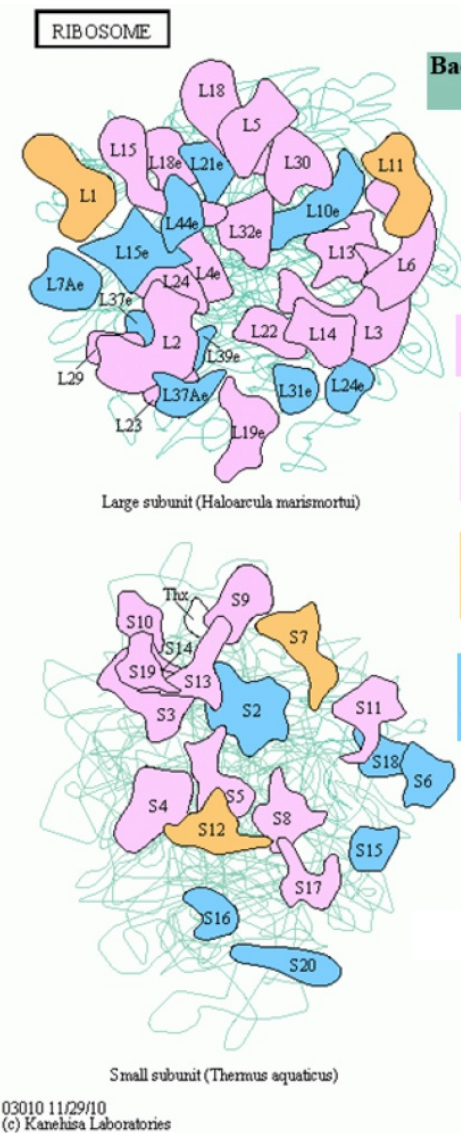

Ribosomal RNAs

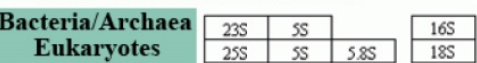

Ribosomal proteins
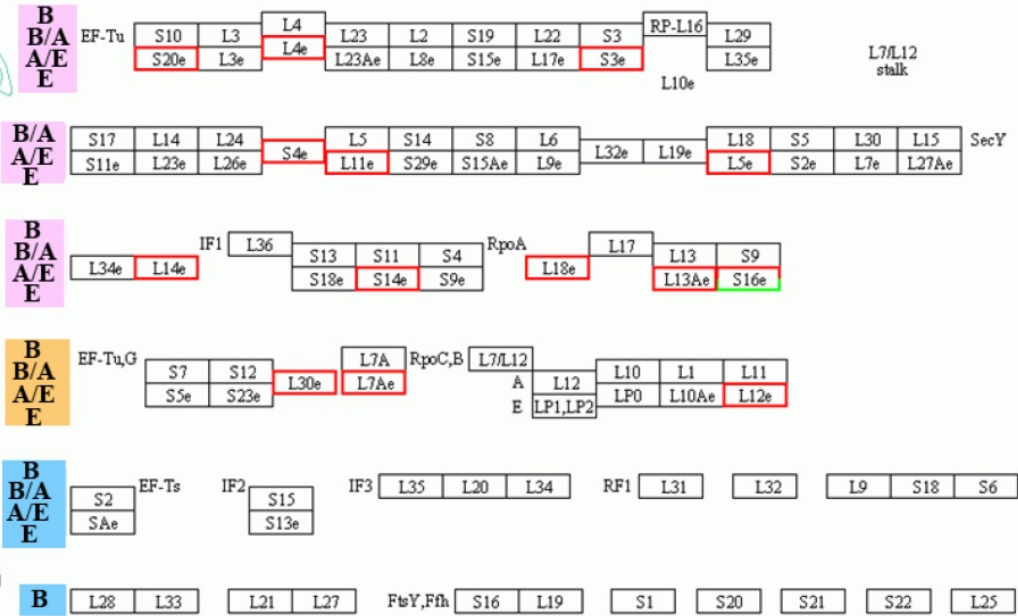

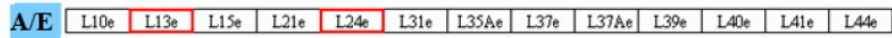

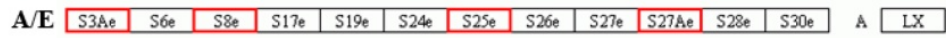

\begin{tabular}{|l|l|l|l|l|l|l|l|}
\hline L 6 E & L18Ae & L22e & L27e & L28e & L29e & L36e & L33e \\
\hline
\end{tabular}

\begin{tabular}{|l|l|l|l|}
\hline E & $S 10 e$ & $S 12 e$ & $S 21 e$ \\
\hline
\end{tabular}

Figure 6. The most significant orthologous enrichment pathway of the significantly differential proteins in spinal cord of the SODI G93A transgenic mice. The most significant orthologous enrichment pathway of the significantly differential proteins in spinal cord of the SOD1 G93A transgenic mice was the ribosome pathway. The proteins in the red frame were the significantly up regulated proteins, that in the green frame were the significantly down regulated proteins, that in the half red and half green frame were the significantly differential proteins of both up and down regulation.

The cluster of orthologous KEGG pathway of the significantly differentially expressed proteins in the spinal cord of the SOD1 G93A transgenic mice

The significantly enriched pathways consisted of the ribosome, the systemic lupus erythematosus, the adherens junction, phagosome, the pathogenic Escherichia coli infection, the leukocyte transendothelial migration, the Wnt signaling pathway, the rheumatoid arthritis, Huntington's disease, lysosome, the amino sugar and nucleotide sugar metabolism, amoebiasis, the synaptic vesicle cycle and the staphylococcus aureus infection (Table $2)$. The details of the molecular interaction and reaction networks of the top 5 of pathways were shown in the figure 6-10. 
SYSTEMIC LUPUS ERYTHEMATOSUS

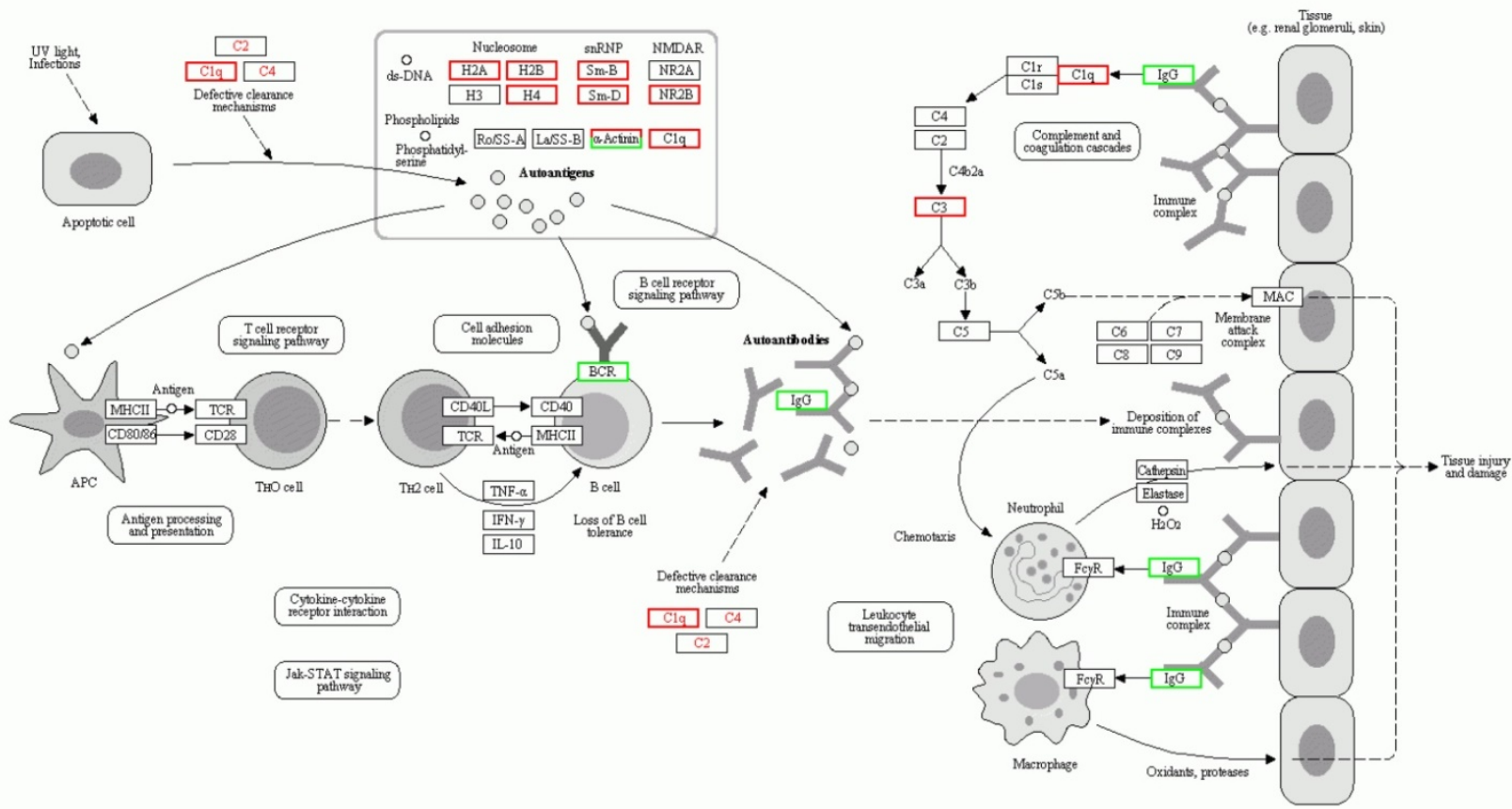

05322828109
(c) Kanehisa Laboratonies

Figure 7. The secondary significant orthologous enrichment pathway of the significantly differential proteins in spinal cord of the SODI G93A transgenic mice. The secondary significant enrichment orthologous pathway of the significantly differential proteins in spinal cord of the SODI G93A transgenic mice was the systemic lupus erythematosus pathway. The proteins in the red frame were the significantly up regulated proteins, that in the green frame were the significantly down regulated proteins, that in the half red and half green frame were the significantly differential proteins of both up and down regulation.

ADHERENS JUNCTION

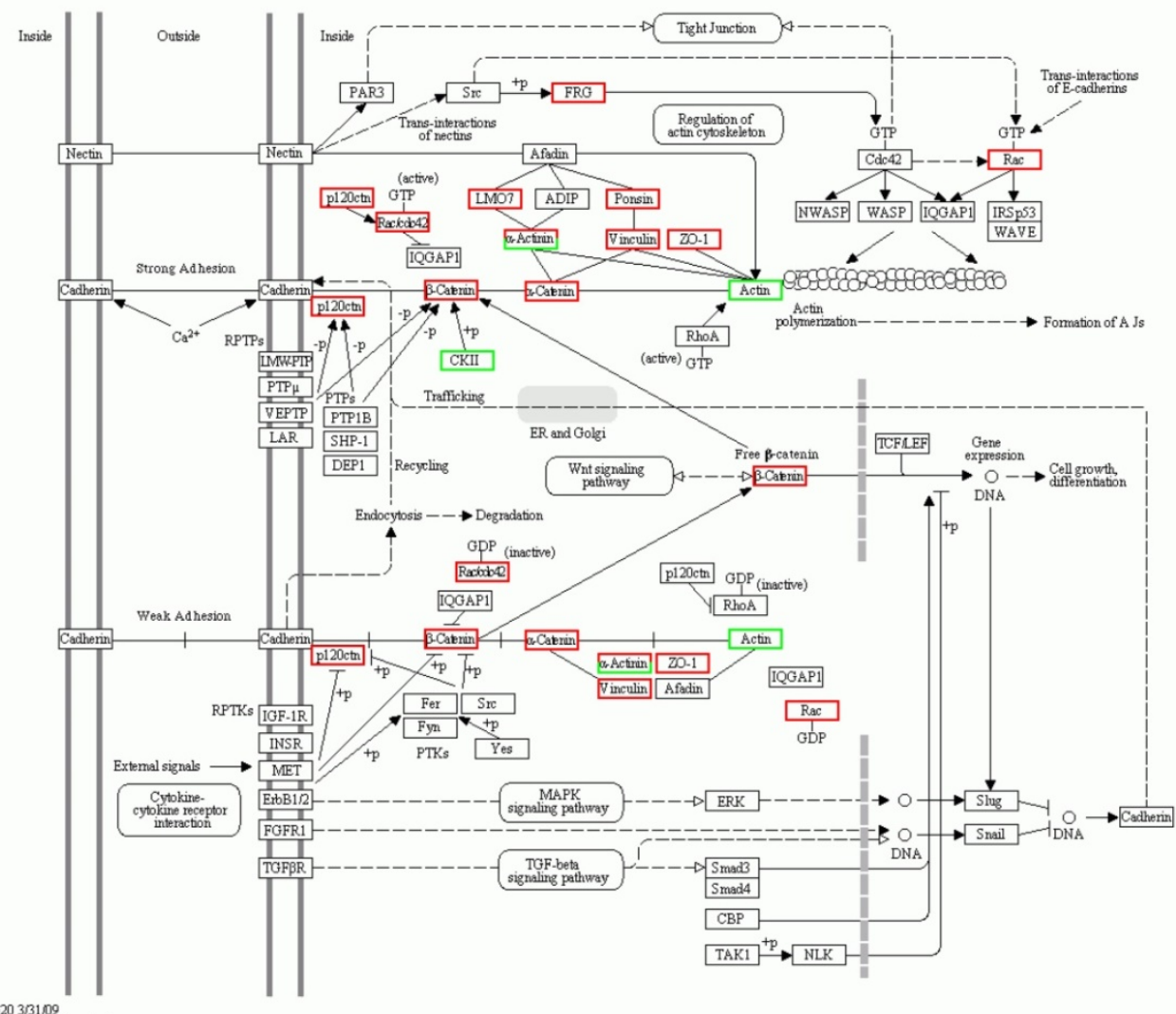

04520331109 (c) Kanchisa Laboratories

Figure 8. The third significant orthologous enrichment pathway of the significantly differential proteins in spinal cord of the SODI G93A transgenic mice. The third significant orthologous enrichment pathway of the significantly differential proteins in spinal cord of the SODI G93A transgenic mice was the adherens junction pathway. The proteins in the red frame were the significantly up regulated proteins, that in the green frame were the significantly down regulated proteins, that in the half red and half green frame were the significantly differential proteins of both up and down regulation. 


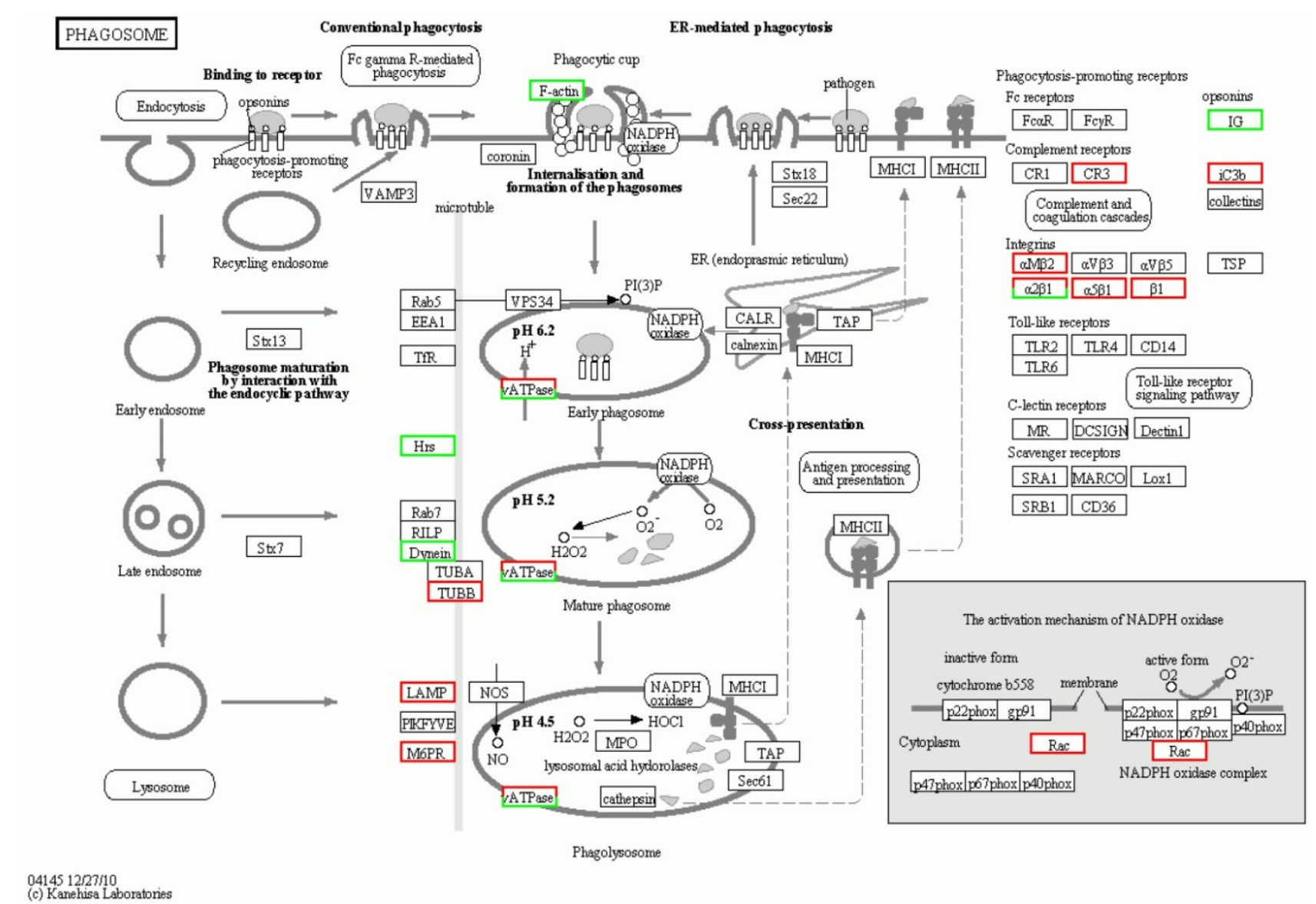

Figure 9. The fourth significant orthologous enrichment pathway of the significantly differential proteins in spinal cord of the SODI G93A transgenic mice. The fourth significant orthologous enrichment pathway of the significantly differential proteins in spinal cord of the SOD1 G93A transgenic mice was the phagosome pathway. The proteins in the red frame were the significantly up regulated proteins, that in the green frame were the significantly down regulated proteins, that in the half red and half green frame were the significantly differential proteins of both up and down regulation.

\section{Discussion}

Our study conducted the comparative proteomic analysis of spinal cord in the SOD1 G93A transgenic mice and the WT mouse by the methods of iTRAQ and biological informatics including COG, GO and the orthologous KEGG pathway. We obtained the following major findings from our results: 1) The upand down-regulation of the multiple complex proteins participated in the pathogenesis at the different disease stages of SOD1 G93A transgenic mice. The up- and down-regulated proteins of major proteins was different at the different disease stages, the up- and down-regulation of fewer partial proteins was involved in the whole stages, which indicated that the up- and down-regulation of the different proteins might play the different roles at the different stages of SOD1 G93A transgenic mice, the partial proteins participated in the whole disease stages possibly play more important role. 2) The up- and down-regulated proteins in the pathogenesis of SOD1 G93A transgenic mice were closely associated with the alterations of the cellular components, molecular functions and biological processes. 3) The up- and down-regulated proteins play some important roles in the pathogenesis of SOD1 G93A transgenic mice through multiple pathways involving in a series of complex molecular mechanisms. This study confirmed that the pathogenesis of ALS involved in multiple complex proteins, not sole one or two proteins, these proteins took part in the complex cellular components, molecular functions and biological processes in the pathogenesis of ALS through multiple pathways.

\section{The significantly differentially expressed proteins in the SOD1 G93A transgenic mice}

In the comparison between the different disease stages (Pre-onset, onset and progression stages) in the spinal cord of SOD1 G93A transgenic mice and the WT mouse, and between the different stages of SOD1 G93A transgenic mice. The number and category of differentially expressed proteins were significantly different at the different stages of SOD1 G93A transgenic mice, among them, the most number and category were in the comparison between the progression stage mouse and the age-matched WT mouse, the up regulated proteins were 676 proteins, 
PATHOGENIC ESCHERICHIA COLI INFECTION

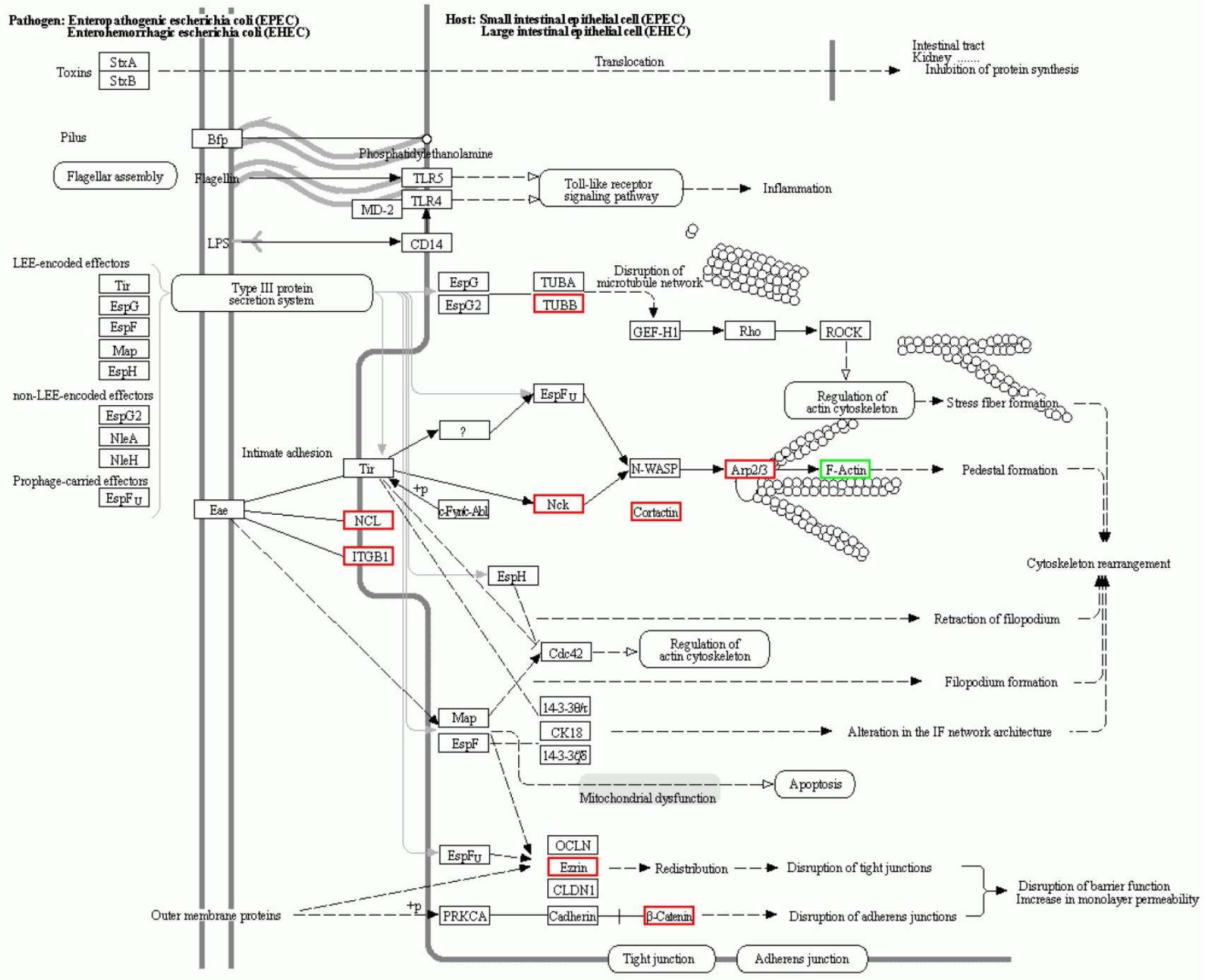

$051305 / 25 / 12$

(c) Kanehisa Laboratories

Figure 10. The fifth significant orthologous enrichment pathway of the significantly differential proteins in spinal cord of the SODI G93A transgenic mice. The fifth significant orthologous enrichment pathway of the significantly differential proteins in spinal cord of the SODI G93A transgenic mice was the pathogenic escherichia coli infection pathway. The proteins in the red frame were the significantly up regulated proteins, that in the green frame were the significantly down regulated proteins, that in the half red and half green frame were the significantly differential proteins of both up and down regulation.

the down regulated were 480 proteins (Figure 1). Therefore, in this study, we focused on comparing and analyzing the relationship between the alteration of proteins at the progression stage and the pathogenesis of ALS. The overlapped proteins in the comparison of the different stages mice and the WT mouse consisted of 134 proteins (Supplementary table 13), the overlapped proteins between the different stages consisted of 111 proteins (Supplementary table 14). The 134 and 111 overlapped proteins might exert more important roles in the pathogenesis of ALS than the other differentially expressed proteins, are worth to further and deeply study them. These proteins involved in a series of biologic functions, their abnormal alterations might be the base and candidate factors of ALS pathogenesis. Our results suggested that the pathogenesis of ALS was produced by the groups of multiple and complex proteins, might not be some single protein contributed ALS. Some proteins might play some key effects in the pathogenesis of ALS [60-64].

\section{The COG analysis of the significantly differentially expressed proteins from the comparison between the progression mouse and the WT mouse}

The COG analysis about the significantly differentially expressed proteins from the comparison between the progression mouse and the WT mouse revealed 18 closely associated functional classifications. They mainly involved in the translation, ribosomal structure and biogenesis, the 
lipid, carbohydrate, amino acid, inorganic ion, nucleotide, coenzyme transport and metabolism; the transcription; the cytoskeletion; the chromatin structure and dynamics; the secondary metabolites, biosynthesis, transport and catabolism; the signal transduction mechanisms; the energy production and conversion; the cell motility; cell cycle control, cell division, chromosome partitioning; replication, recombination and repair; posttranslational modification, protein turnover, chaperons and the general functions (Figure 4). According the results of GO analysis of the significantly differentially expressed proteins, we issued the following hypothesis: In the pathogenesis of ALS, the abnormal expressed proteins possibly resulted in the deficiency of the energetic production due to the disorder of lipid, carbohydrate, coenzyme transport and metabolism and the energy production and conversion [43-46]; the calcium homeostasis because of the abnormal inorganic ion transport and metabolism [47-49]; the disorder of excitability including hypoexcitability, hyperexcitability and excitotoxicity owing to the unbalance of amino acid transport and metabolism [50-52]; the genetic mutations including the damage of mRNA and DNA due to the abnormality of nucleotide transport and metabolism, translation, ribosomal structure and biogenesis, the transcription, replication, recombination and repair $[15,16]$; the abnormal proteomics as a result of the disorder of posttranslational modification, protein turnover, chaperons [60-64]; the excessively apoptotic production in virtue of changes in the secondary metabolites, biosynthesis, transport and catabolism, the signal transduction mechanisms [56-59]. The above described pathogenesis ultimately contributed to the death of neural cells in ALS because of the damage of the cytoskeletion; the chromatin structure and dynamics; the cell motility; the cell cycle control, cell division and chromosome partitioning.

\section{The GO analysis of the significantly differentially expressed proteins from the comparison between the progression mouse and the WT mouse}

We obtained the details of cellular components, molecular functions and biological processes of the significantly differentially expressed proteins from the comparison between the progression mouse and the WT mouse. In the cellular components, these differentially expressed proteins mainly exist in cell, organelle, the macromolecular complex, membrane, and the membrane-enclosed lumen (Figure 5A). In the molecular functions, they mainly participate in binding, and the catalytic, structural molecular, transport and molecular transducer activity (Figure $5 \mathrm{~B})$. In the biological processes, they play the role through the cellular, single-organism, metabolic, biological positive or negative regulation, multicellular organismal, developmental, signaling and reproduction processes; the cellular component organization or biogenesis; the biological regulation; localization; the response to stimulus and the establishment of localization (Figure 5C). These significantly differentially proteins modulate and/or damage their related cellular components, molecular functions and biological processes, participate in the pathogenesis of ALS through a series of complex molecular mechanisms shown in the supplementary table 15-17 and the supplementary figure 1-3. These pathogenesis involved in a series of extensive biologic functions and processes, which indicated that the pathogenesis of ALS wasn't the abnormality of single biologic function or process contributed to ALS, among them, included a lot of complex and mutually implicative biologic functions and processes $[15,16$, 43-52, 56-64]. It might be that their synergistic reactions jointly resulted in the pathogenesis of ALS.

\section{The orthologous pathway enrichment analysis of the significantly differential proteins from the comparison between the progression mouse and the WT mouse}

The significantly orthologous enriched pathways of significantly differential proteins from the comparison between the progression mouse and the WT mouse mainly include 14 pathways (Table 2). Among them, it involves in the multiple intestinal infection pathways including the pathogenic Escherichia coli, the staphylococcus aureus and infection, which indicate the chronic infection of intestine might be one of the pathogenesis of ALS. In addition, it involves in three pathways of autoimmune response like the systemic lupus erythematosus, the rheumatoid arthritis and the leukocyte transendothelial migration, which indicate that the abnormal autoimmune response is one of the pathogenesis of ALS, and there might exist some common pathogenesis between ALS, systemic lupus erythematosus and rheumatoid arthritis. Moreover, the involved pathways of the ribosome, the amino sugar and nucleotide sugar metabolism imply that these differential proteins are associated with the lesion of DNA and/or mRNA, which further support that the damage of the transcription, translation and repair of DNA and/or mRNA play an important role in the pathogenesis of ALS [16, 71]. Meanwhile, these differentially expressed proteins was found to be related to the pathways of the adherens junction, phagosome, the Wnt signaling pathway, the synaptic 
vesicle cycle and lysosome. It implies that these proteins modulate and/or damage the junction, phagosome, the vesicle cycle, lysosome and the Wnt signaling, which might modulate and/or damage the metabolite function of proteins including the degradation, transport, dissolution and phagosome, contribute to the abnormal deposition of proteins, generate the apoptotic neural cell death by the Wnt signaling pathway. Among the orthologous enrichment pathways of these proteins, the involvement of Huntington's disease pathway implies that ALS might have the genetic homology with the other neurodegenerative disease like Huntington's disease. The details of the molecular interaction and reaction networks of the top 5 of pathways were shown in the figure 6-10.

In general, in this study, we reported the details of up and down regulated proteins in the spinal cord of SOD1 G93A transgenic mice, comprehensively analyzed their possible roles in the pathogenesis of ALS. In the COG analysis, found that the differentially expressed proteins mainly caused the deficiency of the energetic production, the calcium homeostasis, the disorder of excitability, the genetic mutations including the damage of mRNA and DNA, the abnormal proteomics and apoptosis. In the GO analysis, these differentially expressed proteins mainly modulate and/or damaged the cell, the organelle, the macromolecular complex, the membrane and the membrane-enclosed lumen in the cellular components; the binding, the catalytic, structural molecular, transport and molecular transducer activity in the molecular functions; the cellular, the single-organism, the metabolic, the biological positive or negative regulation, the multicellular organismal, developmental, signaling and reproducing process, the cellular component organization or biogenesis, the localization, the response to stimulus and the establishment of localization in the biological process. In the orthologous enrichment pathway analysis, the pathways of multiple intestinal infections, three pathways of autoimmune response, the multiple pathways associated with the lesion of DNA and/or mRNA were closely related to the degradation, transport, dissolution and phagosome of proteins. The apoptotic and genetically homological pathways of neurodegeneration were found to participate in the pathogenesis of ALS. Our data suggest that the multiple complex proteins modulate and/or damage the multiple complex molecular functions through the multiple complex pathways involving in a series of complex molecular mechanism, which cross each other or synergistically exert effects in the pathogenesis of ALS.
Finally, it was questionable that we only used one mouse per group, it seen to not accord with the statistically routine requirement. But despite for all that, it didn't bring the important effect for the statistically analysis of data. Main reasons included two elements, one was that we repeated 30 times in the measure of proteins, because the proteins in the same transgenic mice didn't significantly change at the same stage of life, only repeat of measure technology was enough to eliminate the statistical error, didn't need the repeat of animal sample. Another was that our comparison was the fold of each protein, was not the content of each protein. Our method larger reduced the use of animal, was a new try of proteomic studying method. It was better in the ethics of animal care and use, which obtained the same experiment result using the least animal in study. This study was a preliminary part of our series study. In the further studies, we confirmed some significantly up regulated and down regulated proteins by immunofluorescence histochemistry and western blot in spinal cord, brain and SOD1 G93A transfected PC12 cell lines. Among them, partial results have been published [69, 72], which were enough to confirm the reliability of our studying method. Although we could not ensure that all significantly up regulated and down regulated proteins can be confirmed. Our better results [69, 72] should confirm that our studied method and results were confident. Our results provided an important preliminary data for further studying the role of protein abnormality in the pathogenesis of ALS.

\section{Abbreviations}

ALS: amyotrophic lateral sclerosis; TG: B6SJL-Tg(SOD1*G93A)1Gur/J; WT: C57BL/6Jwildtype; PCR: polymerase chain reaction; iTRAQ: isobaric tags for relative and absolute quantitation; SCX: strong cation exchange; LC-ESI-MS/MS: liquid chromatography-electrospray ionization-tandem mass spectrometry; TripleTOF 5600: time-of-flight tandem mass spectrometer; MS: Mass spectrometry; $\mathrm{ACN}$ : acetonitrile; MGF: mascot generic format; GO: gene ontology; COG: the cluster of orthologous groups; KEGG: Kyoto Encyclopedia of Genes and Genomes.

\section{Supplementary Material}

Supplementary figures and tables. http://www.ijbs.com/v14p1306s1.pdf

\section{Acknowledgments}

We sincerely acknowledge the Committee of National Natural Science Foundation of China (30560042, 81160161 and 81360198), Education 
Department of Jiangxi Province (GJJ13198), Jiangxi provincial department of science and technology ([2014]-47, 20142BBG70062, 20142BAB215024), Jiangxi Provincial Department of Science and Technology Gan Po Elite 555 (Jiangxi Finance Elite Education Refers to [2015] 108) and the Innovation Fund Designated for Graduate Students of Jiangxi Province (YC2016-B027, YC2015-S097) for providing the grant to support this study. We also thank for Hua Da gene science and Technology Co., Ltd. for the experimental conduction of the isobaric tags for relative and absolute quantitation (iTRAQ) and the bioinformatics analysis.

\section{Author contributions}

X.S. and Z.J. conceived and designed the experiments. Z.J. H.P. W.S. L.T. L.Y. Z.L. T.Y. and L.Y. performed the experiments, and analyzed the data. X.S. contributed reagents/materials/analysis tools, wrote the paper and finished figures processing. Z.J. H.P. and W.S. were the joint first authors and contributed equally to the work. X.S. was the corresponding author. All authors have been involved in the drafting, critical revision and final approval of the manuscript for publication. All authors agree to be accountable for all aspects of the work in ensuring that questions related to the accuracy or integrity of any part of the work are appropriately investigated and resolved.

\section{Ethical approval}

All animal studies were conducted in accordance with the Guide for the Care and Use of Laboratory Animals of China. All experiments involving animal were reviewed and approved by the ethics committee for animal care and use of the First Affiliated Hospital of Nanchang University, China.

\section{Competing Interests}

The authors have declared that no competing interest exists.

\section{References}

1. Ludolph AC, Brettschneider J, Weishaupt JH. Amyotrophic lateral sclerosis. Current opinion in neurology. 2012; 25: 530-5.

2. Zarei S, Carr K, Reiley L, Diaz K, Guerra O, Altamirano PF, et al. A comprehensive review of amyotrophic lateral sclerosis. Surgical Neurology International. 2015; 6: 171.

3. Kelly Evelyn B. Encyclopedia of human genetics and disease. Santa Barbara, Calif.: Greenwood. 2013; ISBN 978-0-313-38713-5: pp. 79-80.

4. National Institute of Neurological Disorders and Stroke (America) Amyotrophic Lateral Sclerosis (ALS) Fact Sheet. 19 September 2014. Retrieved 2 January 2015.

5. Rowland LP. How amyotrophic lateral sclerosis got its name: the clinical-pathologic genius of Jean-Martin Charcot. Archives of Neurology. 2001; 58: 512-5.

6. Kiernan MC, Vucic S, Cheah BC, Turner MR, Eisen A, Hardiman O, et al. Amyotrophic lateral sclerosis. Lancet. 2011; 377: 942-55.

7. Yoshida S, Mulder DW, Kurland LT, Chu CP, Okazaki H. Follow-up study on amyotrophic lateral sclerosis in Rochester, Minn., 1925 through 1984. Neuroepidemiology. 1986; 5: 61-70.
8. Lilienfeld DE, Perl DP. Projected neurodegenerative disease mortality in the United States, 1990-2040. Neuroepidemiology. 1993; 12: 219-28.

9. McGuire V, Longstreth WT Jr, Koepsell TD, van Belle G. Incidence of amyotrophic lateral sclerosis in three counties in western Washington state. Neurology. 1996; 47: 571-3

10. Sorenson EJ, Stalker AP, Kurland LT, Windebank AJ. Amyotrophic lateral sclerosis in Olmsted County, Minnesota, 1925 to 1998. Neurology. 2002; 59: $280-2$

11. Joseph I Sirven, Barbara L Malamut. Clinical neurology of the older adult (2nd ed.). Philadelphia: Wolters Kluwer Health/Lippincott Williams \& Wilkins. 2008; p. 421.

12. Belbasis L, Bellou V, Evangelou E. Environmental Risk Factors and Amyotrophic Lateral Sclerosis: An Umbrella Review and Critical Assessment of Current Evidence from Systematic Reviews and Meta-Analyses of Observational Studies. Neuroepidemiology. 2016; 46: 96-105.

13. Bozzoni V, Pansarasa O, Diamanti L, Nosari G, Cereda C, Ceroni M. Amyotrophic lateral sclerosis and environmental factors. Functional Neurology. 2016; 31: 7-19.

14. Ingre C, Roos PM, Piehl F, Kamel F, Fang F. Risk factors for amyotrophic lateral sclerosis. Clinical Epidemiology. 2015; 7: 181-93.

15. Morgan S, Orrell RW. Pathogenesis of amyotrophic lateral sclerosis. British medical bulletin. 2016; 119: 87-98

16. Therrien M, Dion PA, Rouleau GA. ALS: Recent Developments from Genetics Studies. Current neurology and neuroscience reports. 2016; 16: 59.

17. Wang MD, Little J, Gomes J, Cashman NR, Krewski D. Identification of risk factors associated with onset and progression of amyotrophic lateral sclerosis using systematic review and meta-analysis. Neurotoxicology. 2017; 61: 101-30.

18. Zufiría M, Gil-Bea FJ, Fernández-Torrón R, Poza JJ, Muñoz-Blanco JL, Rojas-García R, et al. ALS: A bucket of genes, environment, metabolism and unknown ingredients. Progress in neurobiology. 2016; 142: 104-29.

19. Capozzella A, Sacco C, Chighine A, Loreti B, Scala B, Casale T, et al. Work related etiology of amyotrophic lateral sclerosis (ALS): a meta-analysis. Annali di igiene: medicinapreventiva e di comunità. 2014; 26: 456-72.

20. Kang H, Cha ES, Choi GJ, Lee WJ. Amyotrophic lateral sclerosis and agricultural environments: a systematic review. Journal of korean medical science. 2014; 29: 1610-7.

21. Modgil S, Lahiri DK, Sharma VL, Anand A. Role of early life exposure and environment on neurodegeneration: implications on brain disorders. Translational neurodegeneration. 2014; 3: 9.

22. Tanner CM, Goldman SM, Ross GW, Grate SJ. The disease intersection of susceptibility and exposure: chemical exposures and neurodegenerative disease risk. Alzheimer's \& dementia. 2014; 10: S213-25.

23. Yu Y, Su FC, Callaghan BC, Goutman SA, Batterman SA, Feldman EL. Environmental risk factors and amyotrophic lateral sclerosis (ALS): a case-control study of ALS in Michigan. PLoS one. 2014; 9: e101186.

24. Malek AM, Barchowsky A, Bowser R, Heiman-Patterson T, Lacomis D, Rana $\mathrm{S}$, et al. Exposure to hazardous air pollutants and the risk of amyotrophic lateral sclerosis. Environmental pollution. 2015; 197: 181-6.

25. Sánchez-Santed F, Colomina MT, Herrero Hernández E. Organophosphate pesticide exposure and neurodegeneration. Cortex. 2016; 74: 417-26.

26. Su FC, Goutman SA, Chernyak S, Mukherjee B, Callaghan BC, Batterman S, et al. Association of Environmental Toxins With Amyotrophic Lateral Sclerosis. JAMA neurology. 2016; 73: 803-11.

27. Abhinav K, Al-Chalabi A, Hortobagyi T, Leigh PN. Electrical injury and amyotrophic lateral sclerosis: a systematic review of the literature. Journal of neurology, neurosurgery and psychiatry. 2007; 78: 450-3.

28. Beard JD, Engel LS, Richardson DB, Gammon MD, Baird C, Umbach DM, et al. Military service, deployments, and exposures in relation to amyotrophic lateral sclerosis etiology. Environmentinternational. 2016; 91: 104-15.

29. Lacorte E, Ferrigno L, Leoncini E, Corbo M, Boccia S, Vanacore N. Physical activity, and physical activity related to sports, leisure and occupational activity as risk factors for ALS: A systematic review. Neuroscience \& biobehavioral reviews. 2016; 66: 61-79.

30. Vinceti M, Bottecchi I, Fan A, Finkelstein Y, Mandrioli J. Are environmental exposures to selenium, heavy metals, and pesticides risk factors for amyotrophic lateral sclerosis? Reviews on environmental health. 2012; 27: $19-41$

31. Oskarsson B, Horton DK, Mitsumoto H. Potential Environmental Factors in Amyotrophic Lateral Sclerosis. Neurologic clinics. 2015; 33: 877-88.

32. Ravits J. Sporadic amyotrophic lateral sclerosis: a hypothesis of persistent (non-lytic) enteroviral infection. Amyotrophic lateral sclerosis and other motor neuron disorders. 2005; 6: 77-87.

33. De Chiara G, Marcocci ME, Sgarbanti R, Civitelli L, Ripoli C, Piacentini R, et al. Infectious agents and neurodegeneration. Molecular Neurobiology. 2012; 46: 614-38.

34. Kaku M, Simpson DM. HIV neuropathy. Current opinion in HIV and AIDS. 2014; 9: 521-6.

35. Fernández-Borges N, Eraña H, Venegas V, Elezgarai SR, Harrathi C, Castilla J. Animal models for prion-like diseases. Virus research. 2015; 207: 5-24.

36. Limongi D, Baldelli S. Redox Imbalance and Viral Infections in Neurodegenerative Diseases. Oxidative medicine and cellular longevity. 2016; 2016: 6547248

37. Barbeito AG, Mesci P, Boillée S. Motor neuron-immune interactions: the vicious circle of ALS. Journal of neural transmission (Vienna). 2010;117: 981-1000. 
38. Calvo A, Moglia C, Balma M, Chiò A. Involvement of immune response in the pathogenesis of amyotrophic lateral sclerosis: a therapeutic opportunity? CNS \&neurological disorders drug targets. 2010; 9: 325-30.

39. McCombe PA, Henderson RD. The Role of immune and inflammatory mechanisms in ALS. Current molecular medicine. 2011; 11: 246-54.

40. Wood LK, Langford SJ. Motor neuron disease: a chemical perspective. Journal of medicinal chemistry. 2014; 57: 6316-31.

41. Ross CA, Poirier MA. Protein aggregation and neurodegenerative disease. Nature medicine. 2004; 10: S10-7.

42. Pasquali L, Lenzi P, Biagioni F, Siciliano G, Fornai F. Cell to cell spreading of misfolded proteins as a therapeutic target in motor neuron disease. Current medicinal chemistry. 2014; 21: 3508-34.

43. Shi P, Gal J, Kwinter DM, Liu X, Zhu H. Mitochondrial dysfunction in amyotrophic lateral sclerosis. Biochimica et biophysica acta. 2010; 1802: 45-51.

44. Muyderman H, Chen T. Mitochondrial dysfunction in amyotrophic lateral sclerosis - a valid pharmacological target? British journal of pharmacology. 2014; 171: 2191-205.

45. Carrì MT, D'Ambrosi N, Cozzolino M. Pathways to mitochondrial dysfunction in ALS pathogenesis. Biochemical and biophysical research communications. 2017; 483: 1187-93.

46. Parakh S, Spencer DM, Halloran MA, Soo KY, Atkin JD. Redox regulation in amyotrophic lateral sclerosis. Oxidative medicine and cellular longevity. 2013; 2013: 408681.

47. Prell T, Lautenschläger J, Grosskreutz J. Calcium-dependent protein folding in amyotrophic lateral sclerosis. Cell Calcium. 2013; 54: 132-43.

48. Jaiswal MK. Selective vulnerability of motoneuron and perturbed mitochondrial calcium homeostasis in amyotrophic lateral sclerosis: implications for motoneurons specific calcium dysregulation. Molecular and cellular therapies. 2014; $2: 26$.

49. Leal SS, Gomes CM. Calcium dysregulation links ALS defective proteins and motor neuron selective vulnerability. Frontiers in cellular neuroscience. 2015; 9: 225.

50. Shaw PJ, Ince PG. Glutamate, excitotoxicity and amyotrophic lateral sclerosis. Journal of neurology. 1997; 244: S3-14.

51. Foran E, Trotti D. Glutamate transporters and the excitotoxic path to motor neuron degeneration in amyotrophic lateral sclerosis. Antioxidants \& redox signaling. 2009; 11: 1587-602.

52. King AE, Woodhouse A, Kirkcaldie MT, Vickers JC. Excitotoxicity in ALS: Overstimulation, or overreaction? Experimental neurology. 2016; 275: 162-71.

53. Lipton SA, Gu Z, Nakamura T. Inflammatory mediators leading to protein misfolding and uncompetitive/fast off-rate drug therapy for neurodegenerative disorders. International review of neurobiology. 2007; 82: 1-27.

54. Patten DA, Germain M, Kelly MA, Slack RS. Reactive oxygen species: stuck in the middle of neurodegeneration. Journal of alzheimers disease. 2010; 20: S357-67.

55. D'Amico E, Factor-Litvak P, Santella RM, Mitsumoto H. Clinical perspective on oxidative stress in sporadic amyotrophic lateral sclerosis. Free radical biology and medicine. 2013; 65: 509-27.

56. Kermer P, Liman J, Weishaupt JH, Bähr M. Neuronal apoptosis in neurodegenerative diseases: from basic research to clinical application. Neurodegenerative diseases. 2004; 1: 9- 19.

57. Okouchi M, Ekshyyan O, Maracine M, Aw TY. Neuronal apoptosis in neurodegeneration. Antioxidants \& redox signaling. 2007; 9: 1059-96.

58. Ghavami S, Shojaei S, Yeganeh B, Ande SR, Jangamreddy JR, Mehrpour M, et al. Autophagy and apoptosis dysfunction in neurodegenerative disorders. Progress in neurobiology. 2014; 112: 24-49.

59. Radi E, Formichi P, Battisti C, Federico A. Apoptosis and oxidative stress in neurodegenerative diseases. Journal of alzheimers disease. 2014; 42: S125-52.

60. Kaur SJ, McKeown SR, Rashid S. Mutant SOD1 mediated pathogenesis of Amyotrophic Lateral Sclerosis. Gene. 2016; 577: 109-18.

61. Da Cruz S, Cleveland DW. Understanding the role of TDP-43 and FUS/TLS in ALS and beyond. Current opinion in neurobiology. 2011; 21: 904-19.

62. Scotter EL, Chen HJ, Shaw CE. TDP-43 Proteinopathy and ALS: Insights into Disease Mechanisms and Therapeutic Targets. Neurotherapeutics. 2015; 12: 352-63.

63. Rohrer JD, Isaacs AM, Mizielinska S, Mead S, Lashley T, Wray S, et al. C9orf72 expansions in frontotemporal dementia and amyotrophic lateral sclerosis. Lancet neurology. 2015; 14: 291-301.

64. Xiao S, MacNair L, McLean J, McGoldrick P, McKeever P, Soleimani S, et al. C9orf72 isoforms in Amyotrophic Lateral Sclerosis and Frontotemporal Lobar Degeneration. Brain research. 2016; 1647: 43-9.

65. Rosen DR, Siddique T, Patterson D, Figlewicz DA, Sapp P, Hentati A, et al. Mutations in $\mathrm{Cu} / \mathrm{Zn}$ superoxide dismutase gene are associated with familial amyotrophic lateral sclerosis. Nature. 1993; 362: 59-62.

66. Gurney ME, Pu H, Chiu AY, Dal Canto MC, Polchow CY, Alexander DD, et al Motor neuron degeneration in mice that express a human $\mathrm{Cu}, \mathrm{Zn}$ superoxide dismutase mutation. Science. 1994; 264: 1772-5.

67. Henriques A, Pitzer C, Schneider A. Characterization of a novel SOD-1(G93A) transgenic mouse line with very decelerated disease development. PLoS One. 2010; 5: e15445.

68. Zhou Y, Lu Y, Fang X, Zhang J, Li J, Li S, et al. An astrocyte regenerative response from vimentin-containing cells in the spinal cord of amyotrophic lateral sclerosis's disease-like transgenic (G93A SOD1) mice. Neurodegenerative diseases. 2015; 15: 1-12.
69. Liang H, Wu C, Deng Y, Zhu L, Zhang J, Gan W, Tang C, et al. Aldehyde Dehydrogenases 1A2 Expression and Distribution are Potentially Associated with Neuron Death in Spinal Cord of $\operatorname{Tg}\left(\mathrm{SOD} 1{ }^{*} \mathrm{G} 93 \mathrm{~A}\right) 1 \mathrm{Gur}$ Mice. International Journal of Biological Sciences. 2017; 13: 574-87.

70. Chang H, Jiang SF, Dang K, Wang HP, Xu SH, Gao YF. iTRAQ-based proteomic analysis of myofibrillar contents and relevant synthesis and proteolytic proteins in soleus muscle of hibernating Daurian ground squirrels (Spermophilus dauricus). Proteome Science. 2016; 14: 16.

71. Peters OM, Ghasemi M, Brown RH Jr. Emerging mechanisms of molecular pathology in ALS. Journal of clinical investigation. 2015; 125: 1767-79.

72. Zhang J, Liang $\mathrm{H}$, Zhu L, Gan W, Tang C, Li J, et al. Expression and Distribution of Arylsulfatase B are Closely Associated with Neuron Death in SOD1 G93A Transgenic Mice. Molecular Neurobiology. 2018; 55: 1323-37. 